Review Article

\title{
Coevolution between Cancer Activities and Food Structure of Human Being from Southwest China
}

\author{
Yawen Zeng, ${ }^{1}$ Juan Du, ${ }^{1}$ Xiaoying Pu, ${ }^{1}$ Jiazhen Yang, ${ }^{2}$ Tao Yang, \\ Shuming Yang, ${ }^{1}$ and Xiaomeng Yang ${ }^{1}$ \\ ${ }^{1}$ Biotechnology and Genetic Resources Institute, Yunnan Academy of Agricultural Sciences, Kunming 650205, China \\ ${ }^{2}$ Kunming Tiankang Science \& Technology Limited Company, Agricultural Biotechnology Key Laboratory of Yunnan Province, \\ Kunming 650223, China \\ Correspondence should be addressed to Yawen Zeng; zengyw1967@126.com
}

Received 9 June 2015; Accepted 26 July 2015

Academic Editor: Pratheeshkumar Poyil

Copyright (c) 2015 Yawen Zeng et al. This is an open access article distributed under the Creative Commons Attribution License, which permits unrestricted use, distribution, and reproduction in any medium, provided the original work is properly cited.

\begin{abstract}
Yunnan and Tibet are the lowest cancer mortality and the largest producer for anticancer crops (brown rice, barley, buckwheat, tea, walnut, mushrooms, and so forth). Shanghai and Jiangsu province in China have the highest mortality of cancers, which are associated with the sharp decline of barley.
\end{abstract}

\section{Introduction}

Natural products are very popular to combat various physiological threats [1]. Vegetables, fruits, spices, herbs, and beverages have opened up new avenue for the role of phytochemicals in the prevention of human chronic diseases like cancer [2]. Functional foods not only are natural bioactive products with food value and promising cancer prevention and therapy [3], but also prevent diseases, suppress aging, enhance biodefense, bioregulation, and so forth [4]. The biopolymers of edible mushrooms make them very good candidates for formulation of novel functional foods for anticancer and so forth [5]. Greater consumption of fruits and vegetables, as well as whole grain products, appears to lower the risk of multimorbidity [6].

Cancer is becoming the most important public health burden in the world. Its incidence is varying among geographical regions, for example, esophageal cancer high in China, lung cancer in USA, and gallbladder cancer in Chile [7]. Each year 11,844 to 121,442 additional cases of lung cancer, 9,129 to 119,176 cases of bladder cancer, and 10,729 to 110,015 cases of skin cancer worldwide are attributable to inorganic arsenic in food [8]. A diet with higher total diversity may reduce the risk of bladder cancer [9]. The dietary factors are the primary cause of nasopharyngeal cancer [10]. The phytochemicals for anticancer drug design from the green husk of Juglans regia L. have gained attention worldwide [11]. $\beta$-glucans from the cell walls of barley, oat, mushrooms, yeast, seaweeds, algae, and bacteria are essential for new therapeutic strategies against cancer [12].

Southwest China is the only geographical area where functional crop production has significant anticancer effects on humans [13]. Yunnan has not only the largest biodiversity center (higher plants $>18,000$ species; over 500 cultivated plants and 650 species of wild crops), but also the largest reserves of $\mathrm{Al}, \mathrm{Pb}, \mathrm{Zn}, \mathrm{Ti}, \mathrm{Sn}, \mathrm{Cu}$, and $\mathrm{Ni}$ in China [14] and the lowest incidence and mortality of cancers in China. Modern humans originated from Africa between $\sim 100$ and $200 \mathrm{Ka}$, Asia as early as $\sim 130 \mathrm{Ka}$, and Northern Eurasia by $\sim 50 \mathrm{Ka}$ [15]. Hunger due to food shortage with climate change is the cause of early humans' evolution from Africa to Asia and later into Eurasia. Hunger was the cause of migration for early humans' evolution; however, disease prevention of early human migrations was associated with food structure from centers of crop origin, but coevolution between anticancer activities and food structure of human based on crop origin center from Southwest China is unclear. 


\section{Southwest Is the Lowest Mortality of Cancers in China}

The age-standardized incidence rate for cancers in China during 1998 2007 was $1.8586 \%$, 2.0205\%o in men and $1.5915 \%$ o in women in urban areas, but in rural areas it was $2.4434 \%$ o and $1.3790 \%$, respectively [16]. Cancer mortality in China during 2004-2005 was $1.3587 \%$; cancer mortalities of seven regions of China are stated in Table 1: East China (1.6688\%o) $>$ Northeast China $(1.3921 \%$ o $)>$ North China $(1.3126 \%$ ) $>$ Central China (1.2426\%o) > South China $(1.2281 \%$ o $)>$ Northwest China $(1.1433 \%$ ) $>$ Southwest China $(0.9471 \%$ ) [17] (see Table 1). There are significant differences among East China and five other regions (I, IV, V, VI, or VII) for mortality of major cancer; the age-standardized rates of liver cancer in China and world mortalities were $0.184 \%$ and $0.180 \%$, respectively [18]. There are significant differences among South China and six other regions (I, II, III, IV, VI, or VII) for mortality of nasopharyngeal cancer. Nasopharyngeal carcinoma incidence and mortality were obviously higher in South China than in other regions and lowest in North China, and its crude incidence and mortality were $0.0316 \%$ o and $0.0153 \%$, but world age-standardized incidence and mortality were $0.0244 \%$ and $0.0118 \%$, respectively [19].

There are significant differences among Northwest China and six other regions (I, II, III, IV, V, or VI) for mortality of cervical cancer and gastric cancer. Dietary habit was an important factor contributing to gastric cancer, especially regular consumption of fried, grilled, high-salt, high-fat, spicy food and drinking boiled brick tea [20]; Wuwei, a city in Northwest China, has high incidence of gastric cancer, which is because of the carcinogens due to lack of $\mathrm{Vc}$, infection of $\mathrm{Hp}$, atrophic gastritis, and heritage [21].

There are significant differences among Northwest China and three other regions (II, V, or VI) for esophageal cancer $(p<0.05)$; intake of dietary fiber is associated with a reduced risk of esophageal cancer for adults [22], whereas the risk is increased with red meat [23]. Millet exhibits multiple biological activities, including anticancer, antioxidant, immunomodulatory, antifungal, and antihyperglycemia effects [24]; the major genetic split for broomcorn millet divided the accessions into an eastern and a western grouping in Northwestern China [25].

There are significant differences among Southwest China and four other regions (I, II, III, or V) for mortality of breast cancer. Mortality rates increased from Southwest to Northeast and from West to East in China from 1991 to 2011 [26]. There are significant differences among Southwest China and three other regions (I, III, or VII) for mortality of leukemia. There is a significant inverse association between high tea consumption and leukemia risk [27]. The patterns of somatic mutation suggest relevant connections between the functional categories of genes driving acute myeloid leukemia [28]. Xuanwei and Fuyuan of Southwest China have strikingly high incidence of lung cancer, due to food with higher Cd and $\mathrm{Ti}$ contents [29]. Southwest China is not only the region with lowest incidence and mortality of cancers in China [17] (see Table 1), but also a geographical area richest in anticancer crop.

\section{The Lowest Cancer Mortality Associated with Anticancer Crops in Yunnan}

Yunnan province in China spans approximately $394,000 \mathrm{Km}^{2}$. It borders Vietnam, Laos, and Myanmar. Kunming is the provincial capital of Yunnan, and its elevation is $1894 \mathrm{~m}$. Yunnan is not only the cradle of human childhood, a transitional region among East Asia continent, South Asian subcontinent, and Indo-China Peninsula, but also a core integration area of Chinese culture, Indian culture, and Mid-south Peninsula culture which all merge with the local culture [30]. Yunnan province is renowned for three kingdoms of plants, animal, and nonferrous metals, parallel evolution of crop adaptation to nonferrous metals, and anticancer foods for human being are mostly cultivated in this region.

Yunnan is not only the region with lowest incidence and mortality of cancers $(0.541 \%$ ) in China, especially esophageal cancer, gastric cancer, liver cancer, leukemia, female breast cancer, and cervical cancer [17] (see Table 1), but also the largest center of origin and diversity of cultivated crops [13]. The foods/plant extracts of turmeric and Chinese goldthread are more likely to be beneficial against cancer [31]. The cysteine-conjugated metabolites of shogaols are novel dietary colon cancer preventive agents [32]. Consumption of herbal tea is associated with reduced risk of colon cancer, but iced coffee increases rectal cancer risk [33]. Yunnan is not only a core integration area of Vavilov's three centers of crop origin, including Chinese Center, Indian Center, and Central Asiatic Center, but also the largest center of origin and diversity of anticancer crop. Major anticancer food structures for crop are as follows.

3.1. Association of Brown Rice with Anticancer Activities. Rice originates from a single domestication 8.2-13.5 Kya in the Southwest China [34]. In 2013, global rice yield was 700.7 million tons, but Chinese rice yield was 203.3 million tons. Yunnan is a region not only presenting great genetic diversity, but also the center of genetic differentiation of indica and japonica subspecies of Asian cultivated rice; however, pigmented rice with similar wild rice with 2384 accessions accounts for $45.1 \%$ of rice landrace in Yunnan [35], but white rice for present day human consumption accounts for $95 \%$ rice cultivars in China. $M G N-3$ from rice bran may represent a novel adjuvant for the treatment of metastatic breast cancer [36]. The momilactone B in rice bran caused G1 cell cycle arrest and apoptosis in U937 cells, which may be related to anticancer activity [37]. Atractylenolide I might contribute to the anticancer effect of germinated brown rice [38]. The purple rice extract could be developed for functional foods for colon cancer prevention [39]. Human HepG2 cell apoptosis induced by Methanolic-Payao-Purple rice extracts and vinblastine was mediated through a mitochondrial pathway [40]. $\gamma$-Oryzanol, proanthocyanidin, and $\gamma$-tocotrienol in red rice extract may have a potential to serve as food-derived chemotherapeutic agents for cancer patients [41]. Thai purple rice cooked under sterilization could be a potential source of protocatechuic acid exerting high antiproliferative activity [42]. Treatments with peonidin-3-glucoside and cyaniding3-glucoside from black rice extracts significantly reduced 


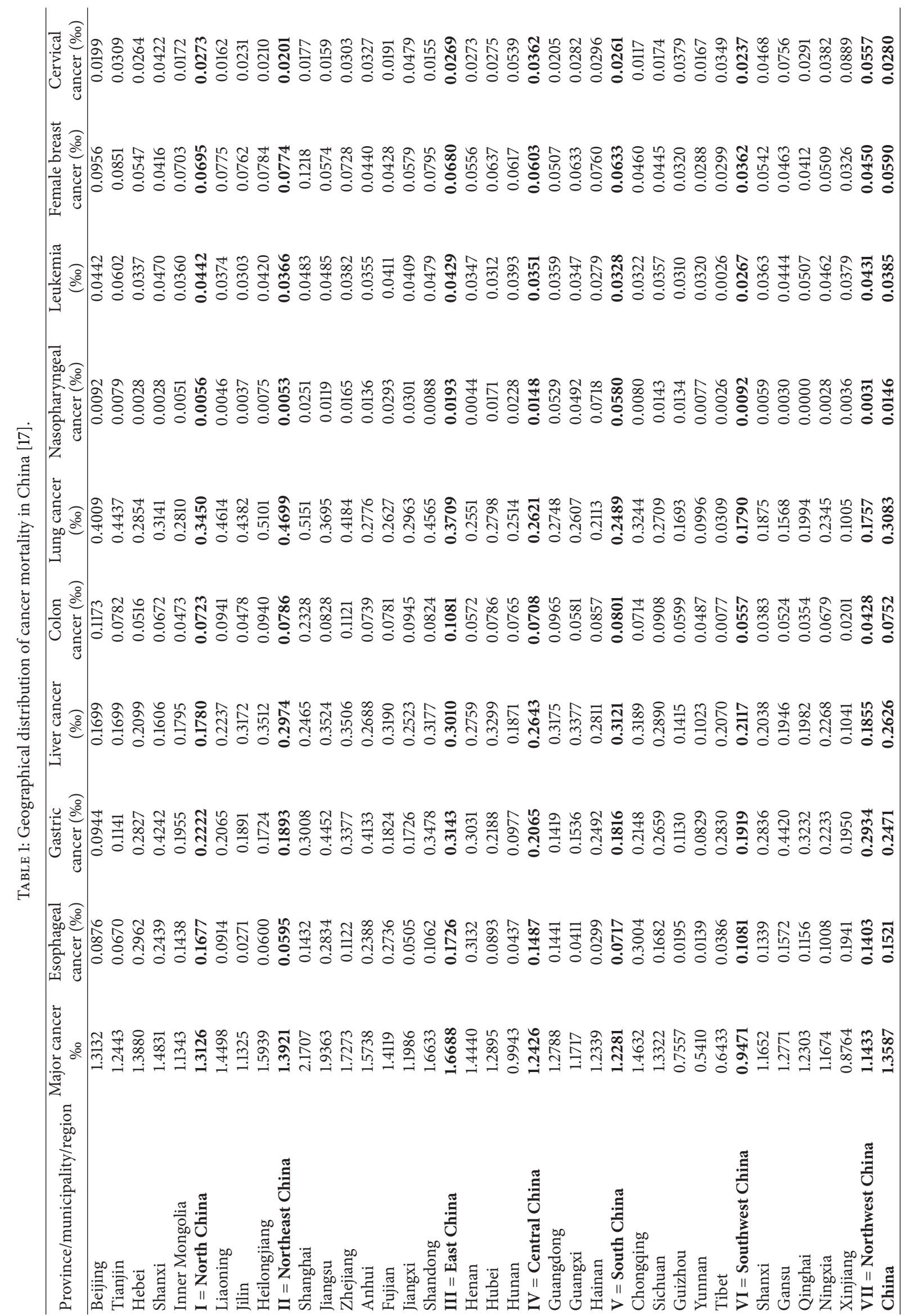


the tumor size and volume in vivo [43]. China and India are the world's largest producers of rice, which account for $26 \%$ and $20 \%$ of all world rice production, respectively. Therefore, Southwest China and North India have the lowest incidence and mortality of cancers associated with origin center of rice, especially pigmented rice.

3.2. Association of Barley with Anticancer Activities. Barley is the most important crop among functional foods [13]. Yunnan is the center of second origin for two naked barleys and the largest diversity center in China [14], as well as the largest Chinese producer. All $\beta$-glucans differ by their length and branching structures, which are considered biological response modifiers with health beneficial effects including anticancer activities [44]. The genotypes of vitamin E $31.5 \mu \mathrm{g} / \mathrm{g}$ dry weight while being of ascorbic acid equivalent antioxidant capacity $158.1 \mathrm{mg} \mathrm{AEAC} / 100 \mathrm{~g}$ fresh weight are potential candidates for breeding of barley cultivars with high vitamin $\mathrm{E}$ content or antioxidant capacity at harvest, even after storage [45]. The content $(\mathrm{mg} / \mathrm{kg})$ of tocotrienols for anticancer activities in barley is higher; that is, barley $(910)>$ rice bran $(465)>$ oat $(210)>$ maize $(200)>$ wheat germ oil (189) > rye (92) [46]. Green barley extract induced preferential antiproliferative and proapoptotic signals within B-lineage leukemia/lymphoma cells [47]. The bioactive compounds in germinated barley and other cereals may reduce the risk of diabetic agents and colon cancer [48]. Protocatechualdehyde present in barley suppressed cell growth and induced apoptosis, which may be a result of deacetylase 2-mediated cyclin D1 suppression [49]. Lunasin present in barley has been observed to prevent skin cancer, which could play an important role in the prevention of cancer in humans [50]. Remarkably high reduction of tumorigenesis and induction of apoptosis in the liver section were achieved in the mouse models with barley-Shochu distillation remnants [51]. Germinated barley foodstuff significantly increased the production of a tumor suppressor gene, which showed promising antineoplastic effects [52].

\subsection{Association of Buckwheat with Anticancer Activities.} Yunnan is not only the center of origins and evolution for buckwheat $[13,14]$, but also the largest Chinese producer of Tartary buckwheat, which accounts for $60.1 \%$ in China. Rutin $(2215.5 \mathrm{mg} / 100 \mathrm{~g}$ at 7 days $)$ and quercitrin $(2301.0 \mathrm{mg} / 100 \mathrm{~g}$ at 8 days) contents after sowing of buckwheat sprouts were approximately 35 and 65 times higher than those of buckwheat seeds [53]. Yunnan golden buckwheat has unique anticancer effects, and its product, "Weimaining" capsules, is the national second-class anticancer drug [54]. TBWSP31 from Tartary buckwheat water-soluble extracts is a novel antitumor protein and apoptosis inducer [55], and also quercetin from its seeds and bran exhibited the strongest cytotoxic effects against the human hepatoma cell line [56]. Tatariside $\mathrm{G}$ may be an effective candidate for chemotherapy against cervical cancer [57].

3.4. Association of Tea with Anticancer Activities. After water, tea is the most widely consumed beverage [58]; tea is cultivated in Asia which is producing more than $91 \%$ of the world. Green tea and quercetin enhanced the therapeutic effect of docetaxel in castration-resistant prostate cancer cells [59]. Green tea polyphenols have strong antioxidants and the inhibition of 16 cancers [13], such as (-)-epigallocatechin-3O-gallate, induces apoptosis in acute myeloid leukemia cells [60]. The articles on the association of tea with cancer are 3214 according to PubMed literature database. Yunnan province in China is center of origin for Camellia sinensis, which has 35 species and 3 varieties, accounting for $76.6 \%$ of Camellia sinensis in the world $[13,14,61]$. There are more than 500 compounds identified. Tea in Yunnan has 15 accessions for $35.0 \%-46.8 \%$ polyphenols and 14 accessions for $5 \%$ caffeine [61]. Epigallocatechin-gallate in green tea has been shown to have antiproliferative activity in colon cancer cells [62]. Catechins of green tea are flavanols, which have many health related characteristics; they especially lower the cytotoxicity and cost of anticancer treatment, inhibit proliferation of breast cancer cells, and block carcinogenesis $[1,63]$. Humans would be able to achieve consistent cancer prevention effects provided there is timely intervention of green tea catechins at appropriate high-dose levels [58]. Green tea and coffee consumption has protective effects on esophageal cancer [64]. Therefore, green tea is the most economic and effective method for anticancer treatment.

3.5. Association of Walnut with Anticancer Activities. Yunnan is not only the center of origins and evolution for fruits, which has 66 families, 134 genus, and 499 species [65], but also the Chinese largest producer of walnut $(2679,000 \mathrm{ha})$, which accounts for $50.2 \%$ of China in 2013. Walnuts are rich in $\omega$-3 fatty acids, tocopherols, $\beta$-sitosterol, and pedunculagin, which slow down the growth of prostate, colon breast, and renal cancers [66]. The tumor size in mice having walnut in their diet was one-fourth than that of the control diet [67]. The $\alpha$-linolenic acid and $\beta$-sitosterol from walnut oil decreased proliferation of MCF-7 cells [68]. Changes in the miRNA expression profiles likely affect target gene transcripts involved in pathways of anti-inflammation, antivascularization, antiproliferation, and apoptosis [69]. Walnuts decrease the risk of these chronic diseases (cancer, type 2 diabetes, cardiovascular disease, and visceral obesity via inflammation) [70]. Dietary walnut can reduce cancer growth and development by its anticancer mechanism of suppressing the activation of $\mathrm{NF} \kappa \mathrm{B}$ [71]. The dihydroxy$3,4^{\prime}$-dimethoxyflavone and regiolone from walnut leaves can induce apoptosis in human breast adenocarcinoma cells [72]. The bioactive compounds in walnut green husks are capable of killing prostate carcinoma cells by inducing apoptosis [11].

3.6. Association of Mushrooms with Anticancer Activities. Yunnan is richest in having species of wild mushrooms in China, which accounts for $90.2 \%$ in China, and $44.1 \%$ in the world. It has 670 species of edible mushrooms, which accounts for $72.4 \%$ in China, including boletes (224 species) and edible boletes (144 species) accounting for $57.4 \%$ and $72.4 \%$ in China, respectively [73]. The export of boletes and Tricholoma matsutake, having anticancer activities, from 
Yunnan province is up to $91,780,000$ and $57,380,000$ USD in 2011 [13]. Medicinal mushrooms have been used to treat cancer, fungal infections, hypertension, diabetes, inflammation, and renal disorders [74]. The most potent extract identified from Ganoderma lucidum inhibited the growth of a gastric cancer cell line by interfering with cellular autophagy and cell cycle [75]. Intake of mushrooms seems to be inversely associated with the epithelial ovarian cancer [76]. Polysaccharides from mushrooms have been widely used in far Asia as antitumor, immunostimulating, antimicrobial, hypocholesterolemic, hypoglycemic, and health-promoting agents [5]. The water extract of Umbilicaria esculenta has a great potential to be developed into an anticancer agent that targets telomerase [77].

3.7. Association of Panax notoginseng with Anticancer Activities. Yunnan is the Chinese largest producer of Panax notoginseng, which accounts for $97 \%$ of the production of China, and more than 400 products were made from it by 1302 companies in China. P. notoginseng is a promising candidate in preventing and treating inflammation-associated colon carcinogenesis [78]. Macroporous resin from the leaves of $P$. notoginseng is enriched with low polarity PPD group saponins of $85 \%$ ethanol fraction, which is a new alternative source of anticancer saponins [79]. A new protopanaxadioltype ginsenoside, 6-O- $\beta$-d-glucopyranosyl-20-O- $\beta$-d-glucopyranosyl-20(S)-protopanaxadiol-3-one (1), was isolated from the roots of $P$. notoginseng, which exhibited cytotoxic activity against five human cancer cell lines [80]. An arabinogalactan RN1 from flowers of Panax notoginseng had an antiangiogenic effect via BMP2 signaling and could be a potential novel inhibitor of angiogenesis [81]. The major saponins in $P$. notoginseng saponin extract were ginsenosides Rg1 (31.1\%) and $R b 1$ (34.4\%), which may provide significant natural defense against human colon cancer [82]. In addition, Yunnan is the richest in species of Amorphophalms knojac $(66.7 \%)$ and its largest producer in China. The konjac glucomannans are associated with a range of health applications which include decreasing the risk of gut cancer and colon carcinogenesis through reduced toxicity of faecal water and precancerous risk factors of human colon cancer [83].

\section{Lower Cancer Mortality Associated with Anticancerous Food in Tibet}

Tibet in China spans approximately over $1,200,000 \mathrm{Km}^{2}$. It borders Myanmar, Bhutan, and Nepal. Tibetans have been adapted to an altitude exceeding 3,500 $\mathrm{m}$ in the early Upper Paleolithic [84]. Tibet is one of the regions with lowest cancer incidence and mortality of cancers (0.643\%o) in China, especially colon cancer, lung cancer, nasopharyngeal cancer, and leukemia [17] (see Table 1). Major anticancer food structures are as follows.

4.1. Association of Naked Barley with Anticancer Activities. Tibet and its vicinity are not only the centers of domestication of cultivated barley $[85,86]$, but also the world's largest producer of naked barley for major food. Barley and its products are good sources of antioxidants [87], especially anticancer. The most common anthocyanin in the purple barley is cyanidin 3-glucoside, whereas delphinidin 3-glucoside is the most abundant anthocyanin in the blue and black groups [87]. Himalaya 292 for barley mutant has high contents of $\beta$ glucan $(9.7 \%)$ and protein $(16.4 \%)$, as well as amylose starch (81.6\%) [88]. The intrinsic differences of $\beta$-glucans in barley and other cereals will elicit variable immune and anticancer responses. The molecular mechanisms of $\beta$-glucan-induced signaling in immune cells are essential for the design of new therapeutic strategies against cancer $[12,89]$. $\beta$-D-glucan from barley regulates breast cancer-relevant gene expression and may be useful for inhibiting endocrine-resistant breast cancer cell proliferation [90]. Whole hulless barley is a functional food that can reduce the prevalence of metabolic syndrome [91].

4.2. Association of Milk with Anticancer Activities. Milk consumption is prevalent in daily diets, and its lactase persistence is likely to have an independent origin in Tibetans [92]. The milk protein $\alpha$-casein would provide a more natural and nontoxic approach to the development of novel anticancer therapies [93].

In addition, Guizhou is not only one of the regions of lower cancer incidence and mortality of cancers $(0.756 \%$ ) in China, but also one of the cradles of human childhood.

\section{The Highest Cancer Mortality Associated with Food in Some Province of China}

Human chronic disease outbreak owes its origin to consumption of brown rice and barley, which were the staple diet of the ancient people, whereas white rice and wheat white flour are now consumed as staple foods of modern people [13]. Yunnan Province is the lowest mortality of cancers $(0.541 \%$ ) in China [17] or all over the world [94], which associated with the largest production base for barley and tea as well as walnut, and so forth in China. East China includes Shanghai, Jiangsu, Zhejiang, Shandong, Anhui, Fujian, and Jiangxi 7 provinces/city, and it is the highest mortality of cancers $(1.6688 \% 0)$ and the most cancer villages (76) in China, which mainly covers some lower reaches of rivers including the Yellow River, Huaihe River, and Yangtze River and also appears near the Dongting Lake and Poyang Lake; the number of cancer villages in China is in turn East China (76) $>$ Central China (28) $>$ North China $(24)=$ South China $(24)>$ Southwest China (12) $>$ Northwest China (3) $=$ Northeast China (3) [95]. The highest cancer mortality associated with barley dropped in some provinces of China, especially Shanghai, Jiangsu, and Zhejiang. Nanjing $(107.3 \mathrm{mg} / \mathrm{kg})$ and Shanghai $(95.59 \mathrm{mg} / \mathrm{kg})$ as well as Hanzhou $(75.7 \mathrm{mg} / \mathrm{kg})$ cities are the highest soil $\mathrm{Pb}^{2+}$ concentrations in 35 cities for China [96]. The lipidtransfer protein from barley grain has an affinity to bind $\mathrm{Co}^{2+}$ and $\mathrm{Pb}^{2+}$ but has no affinity towards $\mathrm{Cd}^{2+}, \mathrm{Cu}^{2+}, \mathrm{Zn}^{2+}$, and $\mathrm{Cr}^{3+}$ [97]. Barley $\beta$-glucan is a radioprotective agent, and it can enhance radioprotection in the human hepatoma cell line HepG2 [98]. Barley with polyphenols possesses many 
other anticarcinogenic activities, and high epicatechin may be related to a reduced risk of breast cancer [99] and colon cancer. Consumption of lunasin from barley could play an important role in cancer prevention [100], but the barley cultivated areas in China in 1935 (6,380,000 ha) were 5.1 times than that in 2012. Shanghai city in 1986 was 6.0 times barley cultivated more than in 2012; Jiangsu province in 1957 $(1,401,400$ ha) was 7.5 times than in 2012; however Zhejiang province in 1935 ( $283800 \mathrm{ha}$ ) was 9.5 times cultivated than in 2012.

Shanghai city has not only the highest cancer mortality $(2.171 \%$ ) in China, especially colon cancer, lung cancer, and female breast cancer [17] (see Table 1) but also has the lowest diversity of cultivated crops, and its elevation is $4.0 \mathrm{~m}$. Colorectal cancer increases by $4.2 \%$ annually in Shanghai, which is faster than the average increasing rate of the world [101]. Lunasin from soybean cotyledon and barley, a peptide with 43 amino acid residues, demonstrated chemopreventive and anticancer properties against colon and breast cancers $[100,102]$. The consumption of barley rice has certain prevention and adjunctive dietary therapy functions for diabetes mellitus, cardiovascular disease, and cancers [103]. Breast cancer is the most common cancer among women in urban China, such as Shanghai, and so forth; however, soy food consumption is significantly associated with decreased risk of breast cancer and lung cancer [104], but cultivated area of soybean in Shanghai is the lowest in China. Fruit intake is inversely associated with the risk of colorectal cancer [105], but cultivated area of fruits in Shanghai is the lowest in China. The high intake of fruits, vegetables, milk, and eggs may reduce the risk of breast cancer, whereas high animal food intake may increase the risk [106]. Age seems to contribute to increased morbidity and mortality of colorectal carcinoma in Yangpu district of Shanghai, but the mortality of colorectal carcinoma appeared higher than the incidence [107].

Jiangsu province has not only the highest cancer mortality (1.936\%o) in China, especially gastric cancer and liver cancer [17] (see Table 1), but also a province of lowest altitude $(<50 \mathrm{~m})$ in China. The elevation of Nanjing in Jiangsu province is $15.6 \mathrm{~m}$. The barley with anticancer cultivated areas of Jiangsu province in China in 1957 (1,401,400 ha) was 7.5 times than in 2012. Cancer outbreak owes its origin to consumption of barley of the ancient people, which is replaced by wheat white flour of modern people. Cancer villages of main production regions of Chinese wheat are in turn Anhui (26) > Shangdong (16) > Henan (15) > Jiangsu (14) >Hebei (12) [95]. There are significant correlations between topsoil $\mathrm{Pb}$ concentration and gastric cancer, as well as grain $\mathrm{Hg}$ concentration with liver cancer in humans [108]. Natural lycopene shows a potential anticancer activity and reduces gastric cancer incidence [109]. The tricin from young green barley leaves on melanin production in B16 melanoma cells inhibits melanin biosynthesis with higher efficacy than arbutin, and it could be used as a whitening agent [110]. The annual average crude incidence and age-standardized incidence by world population were $2.52 \%$ and $1.79 \%$, respectively, but Jiangsu being an area with relatively low risk of female breast cancer presented cancer registry areas from 2006 to 2010 as $0.703 \%$ and $0.481 \%$, respectively [111].
Zhejiang province has very high cancer mortality (1.727\%o) in China, especially for liver cancer [17] (see Table 1). The crude incidence of cancer registered in Zhejiang province in 2009 was 3.202\%o; however, age-standardized incidence by Chinese and world standard population was separately $1.6199 \%$ and $2.0792 \%$; meanwhile, the crude mortality rate was $1.7697 \%$ and the age-standardized mortality by Chinese and world standard population were $0.7917 \%$ and $1.0702 \%$, respectively [112]. The highest soil concentrations in Zhejiang province were $70.36 \mathrm{mg} / \mathrm{kg}$ for $\mathrm{Pb}, 47.49 \mathrm{mg} / \mathrm{kg}$ for $\mathrm{Cr}, 13.51 \mathrm{mg} / \mathrm{kg}$ for As, $0.73 \mathrm{mg} / \mathrm{kg}$ for $\mathrm{Cd}$, and $0.67 \mathrm{mg} / \mathrm{kg}$ for $\mathrm{Hg}$, while $\mathrm{Cd}$ caused the greatest cancer risk [113]. The bioaccumulation of heavy metals in food tubers carries a considerable risk for human cancers [114]. The inhibition of cancer cell viability and apoptosis by protocatechualdehyde in barley leaves may be result of activating transcription factor 3 expression through ERK1/2 and p38-mediated transcriptional activation [115].

\section{Conclusion and Future Prospects}

Chronic disease prevention of early human migrations was associated with food structures from crop origin centers, especially from Asia with four centers of crop origin, which account for $58 \%$ in the world population. The early modern human of Southwest China was related to many ancestors of Asians. Southwest China, richest in anticancer crop, not only is the most important evolution base of Asian and anticancer crops, but also has the lowest mortality and incidence of cancers in China. Yunnan, richest in anticancer crops, is the cradle of human childhood and the lowest cancer incidence as well as mortality of cancers (0.541\%o) in China, especially esophageal cancer, gastric cancer, liver cancer, leukemia, female breast cancer, and cervical cancer, and also the largest center of origin and diversity of functional crops with anticancer activities (brown rice, barley, buckwheat, tea, walnut, mushrooms, Panax notoginseng, Knojac, etc.). Tibet is not only one of the regions of lowest incidence and mortality of cancers $(0.643 \%$ ) in China, especially colon cancer, lung cancer, nasopharyngeal cancer, and leukemia, but also the largest center of origin and diversity of naked barley for major functional foods. Shanghai and Jiangsu, in China, have the highest mortality of cancers (1.936 2.171\%o), which are associated with barley cultivated areas dropped about 6.5 times and 7.5 times, respectively. These results further support that Southwest China (especially Yunnan and Tibet) is the center of lowest mortality of cancers $(0.643 \%$ ) in China based on coevolution between human's anticancer activities and functional foods from crop origin center.
Abbreviations
ALA: Alpha-linolenic acid
EPIYA: Glu-Pro-Ile-Tyr-Ala
HepG2: Liver hepatocellular cells
Hp: Haptoglobin
Ka: 1000 years
$\mathrm{Km}^{2}$ : Square kilometres
Kya: Thousand years ago 
MCF-7 cells: Human breast adenocarcinoma cell line

MGN-3: Arabinoxylan rice bran

$\mathrm{NF} \kappa \mathrm{B}$ : $\quad$ Nuclear factor kappa-light-chain-enhancer

of activated B cells

SNPs: $\quad$ Single nucleotide polymorphisms

TBWSP31: Tartary Buckwheat Protein Fraction

USA: $\quad$ United States of America

USD: United States Dollar

Vc: $\quad$ Vitamin C.

\section{Conflict of Interests}

The authors declare that they have no conflict of interests whatsoever to declare.

\section{Acknowledgments}

This research was supported by the National Natural Science Foundation of China (no. 31260326), China Agriculture Research System (CARS-05), the Science and Technology to Benefit the People (2014RA060), and the Exploit of Emphases New Production (2014BD001) as well as the Yunnan Introduction and Foster Talent Program (2012HB050, 2011CI059) from Yunnan Provincial Scientific and Technology Department. Thanks are due to the professional editing team at Eureka Science for language improvement.

\section{References}

[1] S. Yousaf, M. S. Butt, H. A. R. Suleria, and M. J. Iqbal, "The role of green tea extract and powder in mitigating metabolic syndromes with special reference to hyperglycemia and hypercholesterolemia," Food \& Function, vol. 5, no. 3, pp. 545-556, 2014.

[2] M. Singh, P. Singh, and Y. Shukla, "New strategies in cancer chemoprevention by phytochemicals," Frontiers in Bioscience, vol. 4, no. 1, pp. 426-452, 2012.

[3] E. Ranzato, S. Martinotti, C. M. Calabrese, and G. Calabrese, "Role of nutraceuticals in cancer therapy," Journal of Food Research, vol. 3, no. 4, pp. 18-24, 2014.

[4] T. Mitsuoka, "Development of functional foods," Bioscience of Microbiota, Food and Health, vol. 33, no. 3, pp. 117-128, 2014.

[5] I. Giavasis, "Bioactive fungal polysaccharides as potential functional ingredients in food and nutraceuticals," Current Opinion in Biotechnology, vol. 26, pp. 162-173, 2014.

[6] G. Ruel, Z. Shi, S. Zhen et al., "Association between nutrition and the evolution of multimorbidity: the importance of fruits and vegetables and whole grain products," Clinical Nutrition, vol. 33, no. 3, pp. 513-520, 2014.

[7] J. D. Sharma, M. Kalit, T. Nirmolia, S. P. Saikia, A. Sharma, and D. Barman, "Cancer: scenario and relationship of different geographical areas of the globe with special reference to North East-India," Asian Pacific Journal of Cancer Prevention, vol. 15, no. 8, pp. 3721-3729, 2014.

[8] S. Oberoi, A. Barchowsky, and F. Wu, "The global burden of disease for skin, lung, and bladder cancer caused by arsenic in food," Cancer Epidemiology Biomarkers \& Prevention, vol. 23, no. 7, pp. 1187-1194, 2014.

[9] F. Isa, L.-P. Xie, Z. Hu et al., "Dietary consumption and diet diversity and risk of developing bladder cancer: results from the South and East China case-control study," Cancer Causes and Control, vol. 24, no. 5, pp. 885-895, 2013.

[10] M. C. Yu, "Nasopharyngeal carcinoma: epidemiology and dietary factors," International Agency for Research on Cancer Science Publication, no. 105, pp. 39-47, 1991.

[11] A. A. Alshatwi, T. N. Hasan, G. Shafi et al., "Validation of the antiproliferative effects of organic extracts from the green husk of Juglans regia L. on PC-3 human prostate cancer cells by assessment of apoptosis-related genes," Evidence-Based Complementary and Alternative Medicine, vol. 2012, Article ID 103026, 8 pages, 2012.

[12] S. H. Albeituni and J. Yan, "The effects of $\beta$-glucans on dendritic cells and implications for cancer therapy," Anti-Cancer Agents in Medicinal Chemistry, vol. 13, no. 5, pp. 689-698, 2013.

[13] Y.-W. Zeng, J.-Z. Yang, X.-Y. Pu et al., "Strategies of functional food for cancer prevention in human beings," Asian Pacific Journal of Cancer Prevention, vol. 14, no. 3, pp. 1585-1592, 2013.

[14] Y.-W. Zeng, J.-J. Wang, Z.-Y. Yang et al., “The diversity and sustainable development of crop genetic resources in the Lancang River Valley," Genetic Resources and Crop Evolution, vol. 48, no. 3, pp. 297-306, 2001.

[15] H. Reyes-Centeno, S. Ghirotto, F. Détroit, D. Grimaud-Hervé, G. Barbujani, and K. Harvati, "Genomic and cranial phenotype data support multiple modern human dispersals from Africa and a southern route into Asia," Proceedings of the National Academy of Sciences of the United States of America, vol. 111, no. 20, pp. 7248-7253, 2014.

[16] W.-Q. Chen, R.-S. Zheng, H.-M. Zeng et al., "Trend analysis and prediction of cancer incidence in China," Chinese Journal of Preventive Medicine, vol. 46, no. 7, pp. 581-586, 2012.

[17] M.-G. Zhou, X.-F. Wang, J.-P. Hu et al., "Geographical distribution of cancer mortality in China, 2004-2005," Chinese Journal of Preventive Medicine, vol. 44, no. 4, pp. 303-308, 2010.

[18] K.-R. Wei, X. Yu, R.-S. Zheng et al., "Incidence and mortality of liver cancer in China, 2010," Chinese Journal of Cancer, vol. 33, no. 8, pp. 388-394, 2014.

[19] K.-R. Wei, R.-S. Zheng, S.-W. Zhang et al., "Nasopharyngeal carcinoma incidence and mortality in China in 2010," Chinese Journal of Cancer, vol. 33, no. 8, pp. 381-387, 2014.

[20] S. Yan, B. Li, Z.-Z. Bai et al., "Clinical epidemiology of gastric cancer in Hehuang valley of China: a 10-year epidemiological study of gastric cancer," World Journal of Gastroenterology, vol. 20, no. 30, pp. 10486-10494, 2014.

[21] H.-Z. Luo, D.-H. Mi, T.-Z. Jing et al., "Risk factors of gastric cancer in Wuwei City-an endemic region of gastric cancer," Chinese Journal of Cancer, vol. 24, no. 5, pp. 563-566, 2005.

[22] L. Tang, F. Xu, T. Zhang, J. Lei, C. W. Binns, and A. H. Lee, "Dietary fibre intake associated with reduced risk of oesophageal cancer in Xinjiang, China," Cancer Epidemiology, vol. 37, no. 6, pp. 893-896, 2013.

[23] Y. Choi, S. Song, Y. Song, and J. E. Lee, "Consumption of red and processed meat and esophageal cancer risk: meta-analysis," World Journal of Gastroenterology, vol. 19, no. 7, pp. 1020-1029, 2013.

[24] S. Shan, Z. Li, I. P. Newton, C. Zhao, Z. Li, and M. Guo, "A novel protein extracted from foxtail millet bran displays anticarcinogenic effects in human colon cancer cells," Toxicology Letters, vol. 227, no. 2, pp. 129-138, 2014.

[25] H. V. Hunt, M. G. Campana, M. C. Lawes et al., "Genetic diversity and phylogeography of broomcorn millet (Panicum miliaceum L.) across Eurasia," Molecular ecology, vol. 20, no. 22, pp. 4756-4771, 2011. 
[26] X.-J. Shi, W. W. Au, K.-S. Wu, L.-X. Chen, and K. Lin, "Mortality characteristics and prediction of female breast cancer in China from 1991 to 2011," Asian Pacific Journal of Cancer Prevention, vol. 15, no. 6, pp. 2785-2791, 2014.

[27] S. Zhong, Z. Chen, X. Yu et al., "Tea consumption and leukemia risk: a meta-analysis," Tumor Biology, vol. 35, no. 6, pp. 52055212, 2014.

[28] S.-J. Chen, Y. Shen, and Z. Chen, "A panoramic view of acute myeloid leukemia," Nature Genetics, vol. 45, no. 6, pp. 586-587, 2013.

[29] L. Zhang, J. Lv, and C. Liao, "Dietary exposure estimates of 14 trace elements in Xuanwei and Fuyuan, two high lung cancer incidence areas in China," Biological Trace Element Research, vol. 146, no. 3, pp. 287-292, 2012.

[30] Y.-W. Zeng, J. Du, X.-Y. Pu et al., "Diversity of rice culture associated with ecological environment in Yunnan province of China," Agricultural Science \& Technology, vol. 13, no. 10, pp. 217-226, 2012.

[31] J. Whelan, Y. Zhao, and J. Collier, "Why food matrices are more potent against cancer as compared to their isolated bioactives," The FASEB Journal, vol. 28, no. 1, supplement S647.39, 2014.

[32] J.-S. Fu, H.-D. Chen, D. N. Soroka, R. F. Warin, and S. Sang, "Cysteine-conjugated metabolites of ginger components, shogaols, induce apoptosis through oxidative stress-mediated p53 pathway in human colon cancer cells," Journal of Agricultural and Food Chemistry, vol. 62, no. 20, pp. 4632-4642, 2014.

[33] C. J. Green, P. de Dauwe, T. Boyle, S. M. Tabatabaei, L. Fritschi, and J. S. Heyworth, "Tea, coffee, and milk consumption and colorectal cancer risk," Journal of Epidemiology, vol. 24, no. 2, pp. 146-153, 2014.

[34] X.-H. Huang, N. Kurata, X.-H. Wei et al., "A map of rice genome variation reveals the origin of cultivated rice," Nature, vol. 490, no. 7421, pp. 497-501, 2012.

[35] Y.-W. Zeng, H.-L. Zhang, Z.-L. Li et al., "Evaluation of genetic diversity of rice landraces (Oryza sativa L.) in Yunnan, China," Breeding Science, vol. 57, no. 2, pp. 91-99, 2007.

[36] M. Ghoneum, N. K. Badr El-Din, D. A. Ali, and M. A. ElDein, "Modified arabinoxylan from rice bran, MGN-3/Biobran, sensitizes metastatic breast cancer cells to paclitaxel in Vitro," Anticancer Research, vol. 34, no. 1, pp. 81-87, 2014.

[37] C. Park, N. Y. Jeong, G.-Y. Kim et al., "Momilactone B induces apoptosis and G1 arrest of the cell cycle in human monocytic leukemia U937 cells through downregulation of pRB phosphorylation and induction of the cyclin-dependent kinase inhibitor p21Waf1/Cip1," Oncology Reports, vol. 31, no. 4, pp. 1653-1660, 2014.

[38] T.-I. Jeon, C.-H. Jung, J.-Y. Cho, D. K. Park, and J.-H. Moon, "Identification of an anticancer compound against HT-29 cells from Phellinus linteus grown on germinated brown rice," Asian Pacific Journal of Tropical Biomedicine, vol. 3, no. 10, pp. 785789, 2013.

[39] R. Summart and T. Chewonarin, "Purple rice extract supplemented diet reduces DMH-induced aberrant crypt foci in the rat colon by inhibition of bacterial $\beta$-glucuronidase," Asian Pacific Journal of Cancer Prevention, vol. 15, no. 2, pp. 749-755, 2014.

[40] R. Banjerdpongchai, B. Wudtiwai, and K. Sringarm, "Cytotoxic and apoptotic-inducing effects of purple rice extracts and chemotherapeutic drugs on human cancer cell lines," Asian Pacific Journal of Cancer Prevention, vol. 14, no. 11, pp. 65416548, 2013.
[41] K. Pintha, S. Yodkeeree, P. Pitchakarn, and P. Limtrakul, "Antiinvasive activity against cancer cells of phytochemicals in red jasmine rice (Oryza sativa L.)," Asian Pacific Journal of Cancer Prevention, vol. 15, no. 11, pp. 4601-4607, 2014.

[42] R. Chatthongpisut, S. J. Schwartz, and J. Yongsawatdigul, "Antioxidant activities and antiproliferative activity of Thai purple rice cooked by various methods on human colon cancer cells," Food Chemistry, vol. 188, pp. 99-105, 2015.

[43] W. Liu, J. Xu, S. Wu et al., "Selective anti-proliferation of HER2positive breast cancer cells by anthocyanins identified by highthroughput screening," PLoS ONE, vol. 8, no. 12, Article ID e81586, 2013.

[44] E. Aleem, " $\beta$-glucans and their applications in cancer therapy: focus on human studies," Anti-Cancer Agents in Medicinal Chemistry, vol. 13, no. 5, pp. 709-719, 2013.

[45] T. D. Do, D. Cozzolino, B. Muhlhausler, A. Box, and A. J. Able, "Antioxidant capacity and vitamin E in barley: effect of genotype and storage," Food Chemistry, vol. 187, pp. 65-74, 2015.

[46] B. B. Aggarwal, C. Sundaram, S. Prasad, and R. Kannappan, "Tocotrienols, the vitamin E of the 21st century: its potential against cancer and other chronic diseases," Biochemical Pharmacology, vol. 80, no. 11, pp. 1613-1631, 2010.

[47] E. Robles-Escajeda, D. Lerma, A. M. Nyakeriga et al., "Searching in mother nature for anti-cancer activity: antiproliferative and pro-apoptotic effect elicited by green barley on leukemia/lymphoma cells," PLoS ONE, vol. 8, no. 9, Article ID e73508, 2013.

[48] O. N. Donkor, L. Stojanovska, P. Ginn, J. Ashton, and T. Vasiljevic, "Germinated grains-sources of bioactive compounds," Food Chemistry, vol. 135, no. 3, pp. 950-959, 2012.

[49] J. B. Jeong and S.-H. Lee, "Protocatechualdehyde possesses anticancer activity through downregulating cyclin D1 and HDAC2 in human colorectal cancer cells," Biochemical and Biophysical Research Communications, vol. 430, no. 1, pp. 381-386, 2013.

[50] B. Hernández-Ledesma, C.-C. Hsieh, and B. O. de Lumen, "Lunasin, a novel seed peptide for cancer prevention," Peptides, vol. 30, no. 2, pp. 426-430, 2009.

[51] M. Ohgidani, H. Ichihara, K. Goto, Y. Matsumoto, and R. Ueoka, "Anticancer effects of residual powder from BarleyShochu distillation remnants against the orthotopic xenograft mouse models of hepatocellular carcinoma in vivo," Biological \& Pharmaceutical Bulletin, vol. 35, no. 6, pp. 984-987, 2012.

[52] O. Kanauchi, K. Mitsuyama, A. Andoh, and T. Iwanaga, "Modulation of intestinal environment by prebiotic germinated barley foodstuff prevents chemo-induced colonic carcinogenesis in rats," Oncology Reports, vol. 20, no. 4, pp. 793-801, 2008.

[53] O. Sytar, "Phenolic acids in the inflorescences of different varieties of buckwheat and their antioxidant activity," Journal of King Saud University -Science, vol. 27, no. 2, pp. 136-142, 2015.

[54] J.-Y. Wang, Y.-Z. Wang, Y. Zeng, and J.-T. Li, "Spectrometric determination of trace elements in anticancer new medicine Fagopyrum dibotrys," Spectroscopy and Spectral Analysis, vol. 31, no. 1, pp. 253-255, 2011.

[55] X. Guo, K. Zhu, H. Zhang, and H. Yao, "Anti-tumor activity of a novel protein obtained from tartary buckwheat," International Journal of Molecular Sciences, vol. 11, no. 12, pp. 5201-5211, 2010.

[56] Y. Li, S. Duan, H. Jia, C. Bai, L. Zhang, and Z. Wang, "Flavonoids from tartary buckwheat induce $\mathrm{G}_{2} / \mathrm{M}$ cell cycle arrest and apoptosis in human hepatoma HepG2 cells," Acta Biochimica et Biophysica Sinica, vol. 46, no. 6, pp. 460-470, 2014. 
[57] Y. Li, S.-J. Wang, W. Xia et al., "Effects of tatariside G isolated from Fagopyrum tataricum roots on apoptosis in human cervical cancer HeLa cells," Molecules, vol. 19, no. 8, pp. 11145-11159, 2014.

[58] L. Zhang, Y. Wei, and J. Zhang, "Novel mechanisms of anticancer activities of green tea component epigallocatechin-3gallate," Anti-Cancer Agents in Medicinal Chemistry, vol. 14, no. 6, pp. 779-786, 2014.

[59] P. Wang, S. M. Henning, D. Heber, and J. V. Vadgama, "Sensitization to docetaxel in prostate cancer cells by green tea and quercetin," The Journal of Nutritional Biochemistry, vol. 26, no. 4, pp. 408-415, 2015.

[60] M. Kumazoe, Y. Kim, J. Bae et al., "Phosphodiesterase 5 inhibitor acts as a potent agent sensitizing acute myeloid leukemia cells to $67-\mathrm{kDa}$ laminin receptor-dependent apoptosis," FEBS Letters, vol. 587, no. 18, pp. 3052-3057, 2013.

[61] H.-S. Wang, M. Xu, J. Zhang et al., "Volume tea," in Yunnan Crop Germplasm Resources, X. Q. Huang, Ed., pp. 622-762, Yunnan Science and Technology Press, Kunming, China, 2007.

[62] S. Haratifar, K. A. Meckling, and M. Corredig, "Antiproliferative activity of tea catechins associated with casein micelles, using HT29 colon cancer cells," Journal of Dairy Science, vol. 97, no. 2, pp. 672-678, 2014.

[63] Y. Yu, Y. Deng, B.-M. Lu, Y.-X. Liu, J. Li, and J.-K. Bao, "Green tea catechins: a fresh flavor to anticancer therapy," Apoptosis, vol. 19, no. 1, pp. 1-18, 2014.

[64] J.-S. Zheng, J. Yang, Y.-Q. Fu, T. Huang, Y.-J. Huang, and D. Li, "Effects of green tea, black tea, and coffee consumption on the risk of esophageal cancer: a systematic review and meta-analysis of observational studies," Nutrition and Cancer, vol. 65, no. 1, pp. 1-16, 2013.

[65] W.-B. Zhang, J.-R. Zhang, X.-L. Li et al., "Volume fruit," in Yunnan Crop Germplasm Resources, X. Q. Huang, Ed., pp. 1236, Yunnan Science and Technology Press, Kunming, China, 2007.

[66] W. E. Hardman, "Walnuts have potential for cancer prevention and treatment in mice," The Journal of Nutrition, vol. 144, no. 4, pp. 555S-560S, 2014.

[67] R. J. Reiter, D.-X. Tan, L. C. Manchester et al., "A walnutenriched diet reduces the growth of LNCaP human prostate cancer xenografts in nude mice," Cancer Investigation, vol. 31, no. 6, pp. 365-373, 2013.

[68] J. P. V. Heuvel, B. J. Belda, D. B. Hannon et al., "Mechanistic examination of walnuts in prevention of breast cancer," Nutrition and Cancer, vol. 64, no. 7, pp. 1078-1086, 2012.

[69] M. A. Tsoukas, B. J. Ko, T. R. Witte, F. Dincer, W. E. Hardman, and C. S. Mantzoros, "Dietary walnut suppression of colorectal cancer in mice: mediation by miRNA patterns and fatty acid incorporation," The Journal of Nutritional Biochemistry, vol. 26, no. 7, pp. 776-783, 2015.

[70] C. D. Toner, "Communicating clinical research to reduce cancer risk through diet: walnuts as a case example," Nutrition Research and Practice, vol. 8, no. 4, pp. 347-351, 2014.

[71] W. E. Hardman, "Diet components can suppress inflammation and reduce cancer risk," Nutrition Research and Practice, vol. 8, no. 3, pp. 233-240, 2014.

[72] M. Salimi, M. H. Ardestaniyan, H. M. Kandelous et al., "Antiproliferative and apoptotic activities of constituents of chloroform extract of Juglans regia leaves," Cell Proliferation, vol. 47, no. 2, pp. 172-179, 2014.
[73] G.-Y. Zhang, "Volume edible fungi," in Yunnan Crop Germplasm Resources, X. Q. Huang, Ed., pp. 1-433, Yunnan Science and Technology Press, Kunming, China, 2007.

[74] D. H. Lee and H. W. Kim, "Innate immunity induced by fungal $\beta$-glucans via dectin-1 signaling pathway," International Journal of Medicinal Mushrooms, vol. 16, no. 1, pp. 1-16, 2014.

[75] M. Oliveira, F. S. Reis, D. Sousa et al., "A methanolic extract of Ganoderma lucidum fruiting body inhibits the growth of a gastric cancer cell line and affects cellular autophagy and cell cycle," Food \& Function, vol. 5, no. 7, pp. 1389-1394, 2014.

[76] A. H. Lee, M. Pasalich, D. Su, L. Tang, V. D. Tran, and C. W. Binns, "Mushroom intake and risk of epithelial ovarian cancer in Southern Chinese women," International Journal of Gynecological Cancer, vol. 23, no. 8, pp. 1400-1405, 2013.

[77] B. Xu, C. Li, and C. Sung, "Telomerase inhibitory effects of medicinal mushrooms and lichens, and their anticancer activity," International Journal of Medicinal Mushrooms, vol. 16, no. 1, pp. 17-28, 2014.

[78] X. Wen, C. Wang, C. Yu et al., "Panax notoginseng attenuates experimental colitis in the azoxymethane /dextran sulfate sodium mouse model," Phytotherapy Research, vol. 28, no. 6, pp. 892-898, 2014.

[79] Q. Miao, Y. Li, S.-L. Li, J. Yang, P.-H. Zhang, and Q. Wang, "Chemical profiles and anticancer effects of saponin fractions of different polarity from the leaves of Panax notoginseng," Chinese Journal of Natural Medicines, vol. 12, no. 1, pp. 30-37, 2014.

[80] H.-Z. Fu, R.-J. Zhong, D.-M. Zhang, and D. Wang, "A new protopanaxadiol-type ginsenoside from the roots of Panax notoginseng," Journal of Asian Natural Products Research, vol. 15, no. 10, pp. 1139-1143, 2013.

[81] P.-P. Wang, L. Zhang, J. Yao, Y. Shi, P. Li, and K. Ding, "An arabinogalactan from flowers of Panax notoginseng inhibits angiogenesis by BMP2/Smad/Id1 signaling," Carbohydrate Polymers, vol. 121, pp. 328-335, 2015.

[82] N.-W. He, Y. Zhao, L. Guo, J. Shang, and X.-B. Yang, "Antioxidant, antiproliferative, and pro-apoptotic activities of a saponin extract derived from the roots of Panax notoginseng (Burk.) F.H. Chen," Journal of Medicinal Food, vol. 15, no. 4, pp. 350-359, 2012.

[83] W.-T. Wu and H.-L. Chen, "Effects of konjac glucomannan on putative risk factors for colon carcinogenesis in rats fed a highfat diet," Journal of Agricultural and Food Chemistry, vol. 59, no. 3, pp. 989-994, 2011.

[84] X. Qi, C. Cui, Y. Peng et al., "Genetic evidence of paleolithic colonization and neolithic expansion of modern humans on the Tibetan plateau," Molecular Biology and Evolution, vol. 30, no. 8, pp. 1761-1778, 2013.

[85] F. Dai, E. Nevo, D. Wu et al., "Tibet is one of the centers of domestication of cultivated barley," Proceedings of the National Academy of Sciences of the United States of America, vol. 109, no. 42, pp. 16969-16973, 2012.

[86] X. Ren, E. Nevo, D. Sun, and G. Sun, "Tibet as a potential domestication center of cultivated barley of China," PLoS ONE, vol. 8, no. 5, Article ID e62700, 2013.

[87] M.-J. Kim, J.-N. Hyun, J.-A. Kim et al., "Relationship between phenolic compounds, anthocyanins content and antioxidant activity in colored barley germplasm," Journal of Agricultural and Food Chemistry, vol. 55, no. 12, pp. 4802-4809, 2007.

[88] G. Mann, E. Leyne, Z. Li, and M. K. Morell, "Effects of a novel barley, Himalaya 292, on rheological and breadmaking properties of wheat and barley doughs," Cereal Chemistry, vol. 82 , no. 6, pp. 626-632, 2005. 
[89] G. C.-F. Chan, W. K. Chan, and D. M.-Y. Sze, "The effects of beta-glucan on human immune and cancer cells," Journal of Hematology \& Oncology, vol. 2, article 25, 2009.

[90] Z. M. T. Jafaar, L. M. Litchfield, M. M. Ivanova, B. N. Radde, N. Al-Rayyan, and C. M. Klinge, " $\beta$-D-glucan inhibits endocrineresistant breast cancer cell proliferation and alters gene expression," International Journal of Oncology, vol. 44, no. 4, pp. 13651375, 2014.

[91] L. Gong, L. Gong, and Y. Zhang, "Intake of Tibetan hull-less barley is associated with a reduced risk of metabolic related syndrome in rats fed high-fat-sucrose diets," Nutrients, vol. 6, no. 4, pp. 1635-1648, 2014.

[92] M.-S. Peng, J.-D. He, C.-L. Zhu, S.-F. Wu, J.-Q. Jin, and Y.-P. Zhang, "Lactase persistence may have an independent origin in Tibetan populations from Tibet, China," Journal of Human Genetics, vol. 57, no. 6, pp. 394-397, 2012.

[93] G. Bonuccelli, R. Castello-Cros, F. Capozza et al., "The milk protein $\alpha$-casein functions as a tumor suppressor via activation of STAT1 signaling, effectively preventing breast cancer tumor growth and metastasis," Cell Cycle, vol. 11, no. 21, pp. 3972-3982, 2012.

[94] Y.-W. Zeng, J. Du, X.-Y. Pu et al., “Coevolution between human's anticancer activities and functional foods from crop origin center in the world," Asian Pacific Journal of Cancer Prevention, vol. 16, no. 6, pp. 2119-2128, 2015.

[95] C.-Y. Dong, Y.-L. Tan, M.-L. Luo, and Y. Zhai, "Spatial aggregation pattern of 'cancer village' in China," Geographical Research, vol. 33, no. 11, pp. 2115-2124, 2014.

[96] X.-P. Li, J. Liu, S.-N. Xia et al., "Spatial distribution pattern of lead in urban soil and in children's blood, China," Chinese Journal of Soil Science, vol. 46, no. 1, pp. 226-232, 2015.

[97] S. Gorjanović, D. Sužnjević, M. Beljanski, and J. Hranisavljević, "Barley lipid-transfer protein as heavy metal scavenger," Environmental Chemistry Letters, vol. 2, no. 3, pp. 113-116, 2004.

[98] L. Ghavami, B. Goliaei, B. Taghizadeh, and A. Nikoofar, "Effects of barley $\beta$-glucan on radiation damage in the human hepatoma cell line HepG2," Mutation Research: Genetic Toxicology and Environmental Mutagenesis, vol. 775-776, pp. 1-6, 2014.

[99] J. Luo, Y.-T. Gao, W.-H. Chow et al., "Urinary polyphenols and breast cancer risk: results from the Shanghai Women's Health Study," Breast Cancer Research and Treatment, vol. 120, no. 3, pp. 693-702, 2010.

[100] H. J. Jeong, J. B. Jeong, C. C. Hsieh, B. Hernández-Ledesma, and B. O. de Lumen, "Lunasin is prevalent in barley and is bioavailable and bioactive in in vivo and in vitro studies," Nutrition and Cancer, vol. 62, no. 8, pp. 1113-1119, 2010.

[101] D.-S. Wan, "Epidemiologic trend of and strategies for colorectal cancer," Chinese Journal of Cancer, vol. 28, no. 9, pp. 897-902, 2009.

[102] S. Jia, S. Zhang, H. Yuan, and N. Chen, "Lunasin inhibits cell proliferation via apoptosis and reduces the production of proinflammatory cytokines in cultured rheumatoid arthritis synovial fibroblasts," BioMed Research International, vol. 2015, Article ID 346839, 9 pages, 2015.

[103] J. Jin, W. Long, Y. Zhou et al., "Evaluation for nutritional and healthy effects of barley rice on sale \& prevention and treatment of related chronic epidemics," Food Science and Technology, vol. 40, no. 2, pp. 191-196, 2015.

[104] G. Yang, X.-O. Shu, H.-L. Li et al., "Prediagnosis soy food consumption and lung cancer survival in women," Journal of Clinical Oncology, vol. 31, no. 12, pp. 1548-1553, 2013.
[105] E. Vogtmann, Y.-B. Xiang, H.-L. Li et al., "Fruit and vegetable intake and the risk of colorectal cancer: results from the Shanghai Men's Health Study,' Cancer Causes and Control, vol. 24, no. 11, pp. 1935-1945, 2013.

[106] P.-P. Bao, X.-O. Shu, Y. Zheng et al., "Fruit, vegetable, and animal food intake and breast cancer risk by hormone receptor status," Nutrition and Cancer, vol. 64, no. 6, pp. 806-819, 2012.

[107] X. Han, C. Huang, J. Zhao et al., "Incidence and survival of colorectal carcinoma among permanent residents in Yangpu district of Shanghai, from 2002 to 2012," Chinese Journal of Epidemiology, vol. 35, no. 3, pp. 289-294, 2014.

[108] Q. Zhao, Y. Wang, Y. Cao et al., "Potential health risks of heavy metals in cultivated topsoil and grain, including correlations with human primary liver, lung and gastric cancer, in Anhui province, Eastern China," Science of the Total Environment, vol. 470-471, pp. 340-347, 2014.

[109] M. J. Kim and H. Kim, "Anticancer effect of lycopene in gastric carcinogenesis," Journal of Cancer Prevention, vol. 20, no. 2, pp. 92-96, 2015.

[110] T. X. Meng, N. Irino, and R. Kondo, "Melanin biosynthesis inhibitory activity of a compound isolated from young green barley (Hordeum vulgare L.) in B16 melanoma cells," Journal of Natural Medicines, vol. 69, no. 3, pp. 427-431, 2015.

[111] L.-Z. Wu, R.-Q. Han, J.-Y. Zhou et al., "Incidence and mortality of female breast cancer in Jiangsu, China," Asian Pacific Journal of Cancer Prevention, vol. 15, no. 6, pp. 2727-2732, 2014.

[112] H.-Z. Li, W.-M. Mao, X.-H. Wang et al., "Incidence and mortality of cancer in Zhejiang province in 2009," Chinese Journal of Preventive Medicine, vol. 47, no. 7, pp. 592-596, 2013.

[113] X. Liu, Q. Song, Y. Tang et al., "Human health risk assessment of heavy metals in soil-vegetable system: a multi-medium analysis," Science of the Total Environment, vol. 463-464, pp. 530-540, 2013.

[114] S. Stasinos, C. Nasopoulou, C. Tsikrika, and I. Zabetakis, "The bioaccumulation and physiological effects of heavy metals in carrots, onions, and potatoes and dietary implications for $\mathrm{Cr}$ and Ni: a review," Journal of Food Science, vol. 79, no. 5, pp. R765-R780, 2014.

[115] J. R. Lee, M. H. Lee, H. J. Eo et al., “The contribution of activating transcription factor 3 to apoptosis of human colorectal cancer cells by protocatechualdehyde, a naturally occurring phenolic compound," Archives of Biochemistry and Biophysics, vol. 564, pp. 203-210, 2014. 

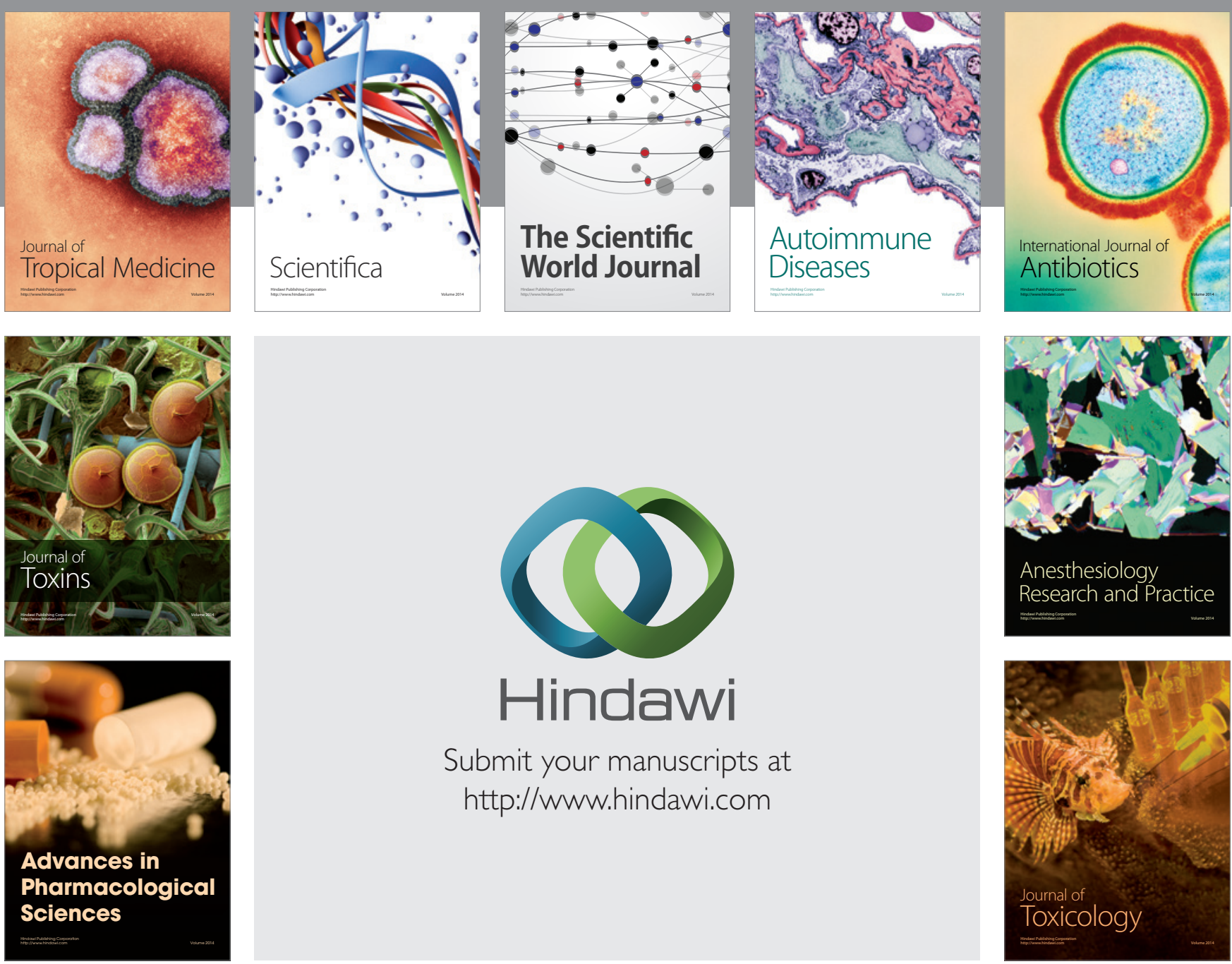

\section{Hindawi}

Submit your manuscripts at

http://www.hindawi.com
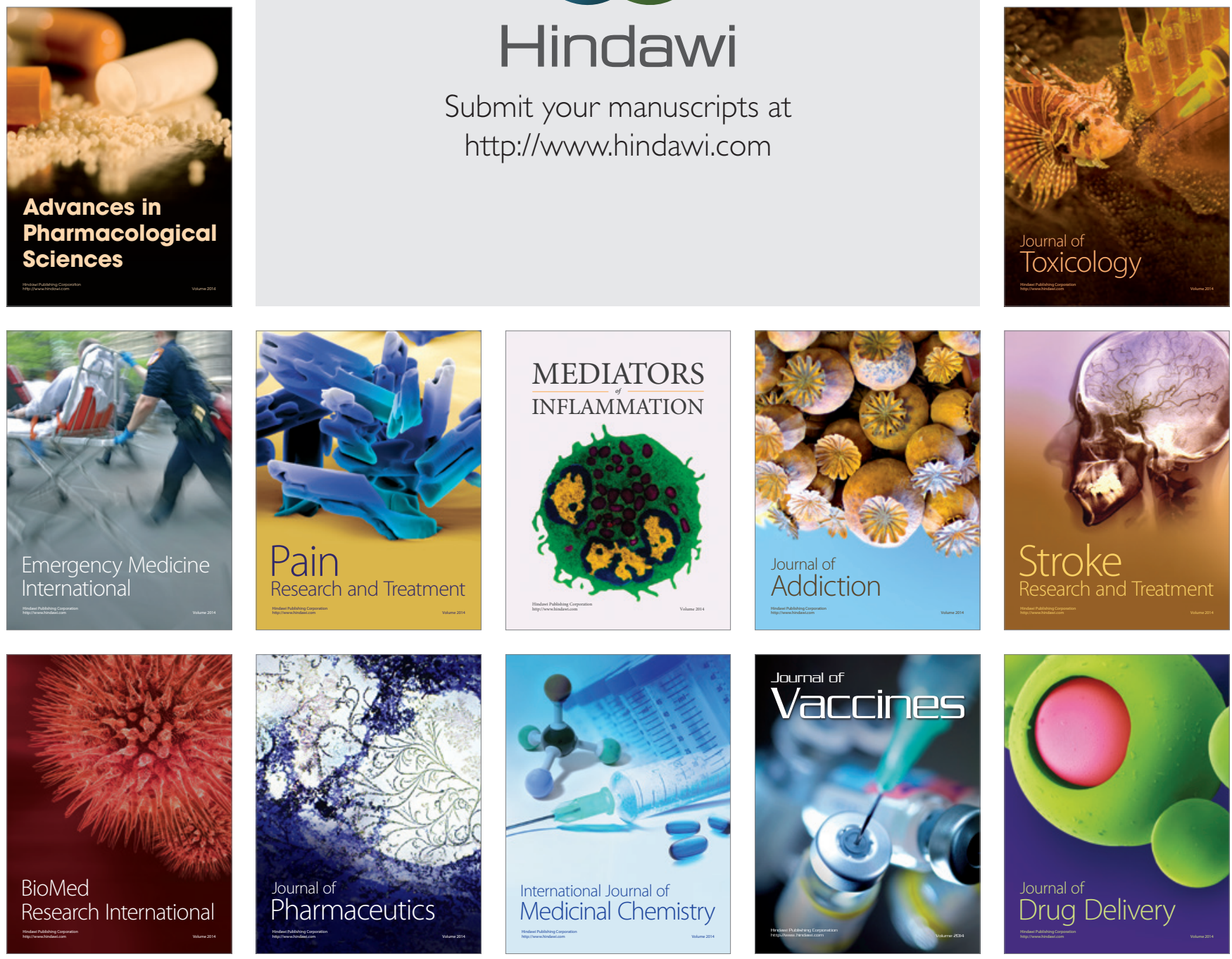